NASA Technical Memorandum 110263

U. S. Army Research Laboratory Memorandum Report 327

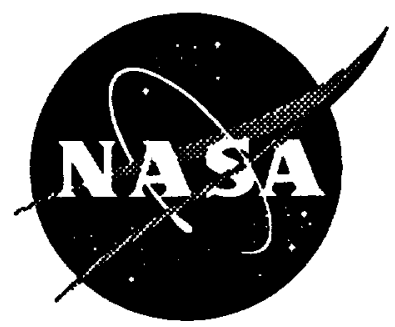

\title{
Test and Analysis of Composite Hat Stringer Pull-off Test Specimens
}

Jian Li

Langley Research Center, Hampton, Virginia

T. Kevin O'Brien

Vehicle Structures Directorate

U.S. Army Research Laboratory

Langley Research Center, Hampton, Virginia

Carl Q. Rousseau

Bell Helicopter Textron, Inc., Fort Worth, Texas

June 1996

National Aeronautics and

Space Administration

Langley Research Center

Hampton, Virginia 23681-0001 



\title{
Test and Analysis of Composite Hat Stringer Pull-off Test Specimens
}

\author{
Jian Li*, T. Kevin O'Brien** and Carl Q. Rousseau***
}

* National Research Council Resident Research Associate, NASA Langley Research Center, Hampton, VA.

** Senior Scientist, U.S. Army Research Laboratory, NASA Langley Research Center, Hampton, VA.

*** Engineering Specialist, Bell Helicopter Textron, Inc. Fort Worth, TX

\begin{abstract}
Hat stringer pull-off tests were performed to evaluate the delamination failure mechanisms in the flange region for a rod-reinforced hat stringer section. A special test fixture was used to pull the hat off the stringer while reacting the pull-off load through roller supports at both stringer flanges. Microscopic examinations of the failed specimens revealed that failure occurred at the ply termination in the flange area where the flange of the stiffener is built up by adding $45 /-45$ tape plies on the top surface. Test results indicated that the as-manufactured microstructure in the flange region has a strong influence on the delamination initiation and the associated pulloff loads. Finite element models were created for each specimen with a detailed mesh based on micrographs of the critical location. A fracture mechanics approach and a mixed mode delamination criterion were used to predict the onset of delamination and the pull-off load. By modeling the critical local details of each specimen from micrographs, the model was able to accurately predict the hat stringer pull-off loads and replicate the variabilty in the test results.
\end{abstract}

\section{Introduction}

Rod-reinforced advanced composite structures are being developed for increased compression strength and reduced manufacturing cost [1]. One example is the rodpack hat stringer 
developed for tiltrotor wing applications. Previous rodpack hat stringer compression tests [1,2] indicated that the initial failure mode involves the skin buckling away from the hat. A possible source of this buckling instability is a delamination growing from the free edge of the flange. To understand this local failure mechanism, specimens were cut from a full-size hat stringer panel manufactured by Bell Helicopter and tested monotonically to failure in a special fixture developed at NASA Langley which provides a mechanism to pull the hat off the stringer and to react the pull-off load at both flanges.

The first objective of this paper was to understand the failure mechanisms of the pull-off specimens, and sources that contribute to their failures. The second objective was to develop an analytical methodology to accurately predict the delamination onset and the associated pull-off load. In the paper, the test results of nine hat stringer pull-off specimens are provided first, followed by finite element analyses of these specimens that take into account the local details in each individual specimen, such as ply termination, resin pockets, and ply waviness at the critical location. A fracture mechanics approach and a mixed mode delamination criterion were used to predict the onset of delamination and the pull-off load. By modeling the critical local details of each specimen from micrographs, the model was able to accurately predict the hat stringer pull-off loads and replicate the scatter in the test results.

\section{Experimental Investigation}

\section{Specimen Configuration}

A typical specimen is a section of a single hat stringer, as shown in Figure 1, where the span is $178 \mathrm{~mm}$ (seven inches). A total of nine specimens, three each with three different widths, were tested. The specimen widths were $25 \mathrm{~mm}$ (one inch), $50 \mathrm{~mm}$ (two inches) and $75 \mathrm{~mm}$ (three inches). The stringer was made of IM7/E7T1-2 graphite epoxy tape with $\pm 45^{\circ}$ plies. In addition, the stringer had precured pultruded graphite/epoxy rods in the skin beneath the hat 
stiffener and also in the cap of the hat stiffener to provide compressive strength to the stringer (Figure 1).

\section{Experimental Procedure}

Experiments were conducted in a servo-hydraulic load frame using a special fixture developed at NASA Langley as shown in Figure 2. The fixture provides a mechanism to pull the hat off the stringer and roller supports to react the pull-off load at both flanges of the stringer. The roller supports are moveable to install and remove the specimen and to provide different support locations on the flanges (see Figure 1). The specimens were loaded monotonically in stroke control until failure. A plot of the applied load versus hat displacement was recorded on an XY plotter for each specimen.

\section{Test Results}

A typical load-displacement curve is shown in Figure 3. Except for the initial non-linearity due to the compression of the rubber pad placed in the top cap of the hat (Figure 1), the curve is almost linear up to a sudden failure and associated load drop. The test was stopped at that point, and the specimen was removed from the fixture and specimen edges were examined under a light microscope. All the specimens failed in the area where the flange, consisting of \pm 45 tape plies, terminated. The maximum pull-off load, normalized by specimen width, is shown in Table 1. In the table, specimens with a one inch width were denoted $3 \mathrm{~A} 1$, two inch widths were denoted $3 \mathrm{~A} 2$, and three inch widths were denoted $3 \mathrm{~A} 3$, respectively. The results are presented in ascending order of failure loads. There is no order of pull-off loads in terms of the specimen width. There is a large variability in the normalized maximum pull-off loads, even though all the specimens came from a single three stringer panel. The pull-off loads measured on the nine specimens have a coefficient of variation of $17 \%$. 
Micrographs of failed specimens are shown in Figure 4 from left to right and from top to bottom in the order of increasing maximum pull-off load per unit width. These microscopic examinations of the failed specimens revealed that there were noticeable differences in plytermination, resin pocket geometry and ply waviness at the critical location (see Figure 1). In most cases, delamination initiated at the first ply termination nearest the continuous skin plies and the terminated flange plies seperated from the continuous skin plies.

A relationship between the maximum pull-off loads and the as-manufactured microstructures seems to exist. Two of the three specimens (3A1-3, 3A3-2 and 3A1-1) with a resin pocket that cracked away from the terminated ply had the lowest pull-off loads. All specimens had some waviness, but the specimens (3A1-3,3A3-2 and 3A1-2) with the most waviness (most compaction under the flange) had the lowest pull-off loads. Also, specimen 3A1-3 failed by delamination from a vertical crack in the middle of the resin pocket at the end of a two-ply termination and had a much lower maximum pull-off load than the rest of the specimens that had smaller resin pockets at the end of a single ply termination. Hence, in addition to modeling the as-designed microstructure, finite element analyses capable of modeling the actual asmanufactured microstructural geometry at the failure location were performed to try to explain the relative significance of these manufacturing anomalies.

\section{Analytical Investigation}

\section{Fracture Mechanics Approach}

From the experimental observations, it was assumed that unstable delamination growth from a resin pocket crack caused the catastrophic failure of the specimen. Hence a fracture mechanics approach was used to analyze the delamination phenomena. The analysis assumes that a crack has formed in the resin pocket or between the resin pocket and the ply termination as seen from the micrographs in Figure 4. Delaminations are typically mixed-mode-fracture phenomena, 
consisting of a combination of an opening mode I, due to interlaminar tension, a sliding shear mode II, due to interlaminar shear, and a scissoring shear mode III, due to anti-plane shear. The total strain energy release rate, $G_{T}$, physically corresponds to the loss of strain energy as new delamination surface area is created and consists of contributions due to opening mode fracture, $G_{I}$, sliding shear fracture, $G_{I I}$, and scissoring shear fracture, $G_{I I I}$. Hence, $G_{T}=G_{I}+$ $\mathrm{G}_{\mathrm{II}}+\mathrm{G}_{\mathrm{II}}$. In these types of specimen configurations, a plane stress state is introduced in the analysis and the mode III contribution is neglected. In the present analysis then $G_{T}=G_{I}+G_{I I}$. To implement the fracture mechanics analysis, a finite element model was developed with the resin crack, and a simulated delamination running from this crack, to calculate the total strain energy release rate $\left(\mathrm{G}_{\mathrm{T}}\right)$ and the mixed mode ratio $\left(\mathrm{G}_{\mathrm{II}} / \mathrm{G}_{\mathrm{T}}\right)$. With the help of mixed mode fracture criterion as described below, the fracture toughness $\left(\mathrm{G}_{\mathrm{c}}\right)$ at that mixed mode ratio can be determined, and subsequently used to calculate the pull-off load required to initiate and grow the delamination in a catastrophic manner. The $\mathrm{G}_{\mathrm{T}}$ is proportional to the square of the applied load [3], P, i.e.

$$
\mathrm{G}_{\mathrm{T}}=\lambda \mathrm{P}^{2}
$$

where $\lambda$ is the constant of proportionality determined from the finite element analysis. Hence, the critical load, $P_{c}$, at fracture is calculated as

$$
P_{c}=\sqrt{\frac{G_{c}}{\lambda}}
$$

\section{Mixed-Mode Delamination Fracture Criterion}

The mixed mode delamination fracture criterion employed here is based on three individual interlaminar fracture toughness tests for unidirectional composites that were generated from a Round Robin series of interlaboratory tests conducted within ASTM committee D-30 on composites. The three tests are the double cantilever beam (DCB) test [4] for mode I fracture 
toughness $\left(G_{I c}\right)$, the end notch flexure (ENF) test $[5,6]$ for mode II fracture toughness $\left(G_{\Pi \mathrm{Ic}}\right)$, and the mixed mode bending (MMB) test [7] for mixed mode I and mode II fracture toughness. For the MMB test, three mixed mode ratios are considered: $\mathrm{G}_{\mathrm{II}} / \mathrm{G}_{\mathrm{T}}=20 \%, 50 \%, 80 \%$. The results of these tests for the IM7/E7T1-2 graphite/epoxy unidirectional composites are shown in Figure 5, where the average mixed mode fracture toughness along with its scatter band is plotted against the mixed mode ratio $\mathrm{G}_{\mathrm{I}} / \mathrm{G}_{\mathrm{T}}$. When the mixed mode ratio is zero, the mixed mode fracture toughness is simply the mode I fracture toughness. Alternatively, the mixed mode fracture toughness becomes the mode II fracture toughness when the mixed mode ratio is $100 \%$. An equation resulting from a regression cubic curve fit to these test data defines the mixed mode delamination fracture criterion for each mixed mode ratio. The cubic fit to the data shown in Figure 5 is given by

$$
G_{c}=M_{0}+M_{1}\left(\frac{G_{I I}}{G_{T}}\right)+M_{2}\left(\frac{G_{I I}}{G_{T}}\right)^{2}+M_{3}\left(\frac{G_{I I}}{G_{T}}\right)^{3}
$$

where the fitting parameters are $M_{0}=167.49, M_{1}=4.3965, M_{2}=-0.068898$ and $M_{3}=0.0022075$, respectively.

\section{Finite Element Model}

The skin-flange region on either side of the hat stringer is modeled as indicated in Figure 6. The critical region where the delamination initiates is at the skin-flange built up area on either side of the hat stiffener. Hence, only a section of the skin and flange on one side of the curve region needs to be studied. A statically equivalent clamped boundary condition is placed at the cut-off location. This simplification is justifiable because the critical region is far from the clamped location. The simplified model shown in Figure 6 differs from the real situation only by a small rigid body translation and a small rotation. In small deformation linear elasticity,

these rigid body motions have no effect on the computation of strain energy release rate which 
is evaluated using forces and relative displacements of the delamination surfaces to determine the change in the strain energy as the delamination grows.

Finite element models were created for each of the nine specimens in order to obtain the proportionality coefficient, $\lambda$, and the mixed mode ratio, $\mathrm{G}_{\mathrm{II}} / \mathrm{G}_{\mathrm{T}}$, corresponding to the asmanufactured microstructure. A typical finite element model (specimen 3A1-2) is shown in Figure 7, where $D_{1}$ and $D_{2}$ denote the thicknesses of the skin and skin plus flange, respectively. The lengths of the skin region, the detailed region, the remaining tapered region and the flange region are denoted as $\mathrm{L}_{1}, \mathrm{~L}_{2}, \mathrm{~L}_{3}$ and $\mathrm{L}_{4}$, respectively.

A special feature of the present finite element model is the detailed modeling at the critical region. The detailed finite element meshes are created from micrographs. A flow chart in Figure 8 presents the process. Micrographs of the polished edge of a specimen are taken first. Figure 9 shows an example of a micrograph for specimen 3A1-2. These pictures are scanned into a computer. The scanned images are used to generate the detailed geometries required in finite element modeling. This is done by using a recently developed software package to generate geometric points and surfaces from a scanned image and to convert layer material properties into the cross section plane. The software is called MEGS (Modeling Exact Geometry from Scanned Images) and was developed inhouse at NASA Langley. The geometric information and material property sets created by using MEGS are read into MSC/PATRAN ${ }^{\circledR}$ to create the finite element model. The finite element model is analyzed by using the MSC/NASTRAN ${ }^{\circledR}$ finite element analysis package (solution 101 for linear static analysis), and the forces at the delamination front and the displacements ahead of the delamination front are used to compute strain energy release rates using the virtual crack closure technique (VCCT) [8]. 
Figure 10 shows a detailed finite element mesh at the critical location in specimen $3 \mathrm{~A} 1-2$. The finite element mesh consists mostly of 4-noded quadrilateral shell elements (CQUAD4) and some triangular shell elements (CTRIA3). The elements with neat resin properties are shown as a shaded region. The circles in Figure 10 denote double nodes with fixed multipoint constraints (MPC). The scanned image and the detailed finite element mesh at the critical region for specimen 3A1-3 are shown in Figure 11 and Figure 12, respectively. Specimen 3A1-3 has a two-ply termination which is different from the rest. The multipoint constraints were released systematically to calculate the strain energy release rate components as a function of delamination length, $a$. Convergence was evaluated by refining the elements around the delamination tip region. There were no significant changes in the calculated Mode I and Mode II strain energy release rate components from an initial element length of one half of a ply thickness down to a quarter of a ply thickness. Similar behavior was observed in Ref. 9 . Subsequently, a half-ply thickness element length was used in the delamination tip region for all the models. The material properties for unidirectional IM7/E7T1-2 lamina and neat resin are presented in Table 2.

The total strain energy release rate, $G_{T}$, and the mode $I$ and mode $\Pi$ components, $G_{I} \& G_{\Pi}$, are plotted in Figure 13 for various values of delamination length, $a$, for the 3A1-2 specimen at an assumed pull-off load of $14 \mathrm{kN} / \mathrm{m}$. As shown in Figure 13, the strain energy release rate values increase as the delamination length increases, which indicates unstable delamination growth once the delamination toughness value is reached. Hence, the $G$ value calculated at the first delamination growth increament, $\Delta a$, in Figure 13 were used to determine the mixed mode ratio, $G_{I I} / G_{T}$, and the corresponding $G_{c}$ from Equation (3). The proportionality coefficient, $\lambda$, from Equation (1), and the maximum pull-off load from Equation (2) were then determined using $G_{T}, P$, and $G_{c}$. Finite element models for the other eight specimens also calculated increasing $G$ values with increasing delamination length. 
Because the as-manufactured geometric details are unknown in routine stress analysis of an actual part, an idealized model was also constructed based on the as-designed shape of a typical specimen. The detailed mesh at this location is shown in Figure 14. The geometry of the idealized model is given by: $\mathrm{D}_{1}=2.14 \mathrm{~mm}, \mathrm{D}_{2}=5.56 \mathrm{~mm}, \mathrm{~L}_{1}=25.4 \mathrm{~mm}, \mathrm{~L}_{2}+\mathrm{L}_{3}=14.3 \mathrm{~mm}$, and $\mathrm{L}_{4}=14.3 \mathrm{~mm}$. The difference from the as-manufactured models is in the details at the critical location. The idealized model assumes a single ply termination but uniform rather than irregular triangular resin pockets and straight rather than the wavy plies that typically were observed in the as-manufactured specimens. Stress analysis of the idealized model indicates the most likely place to develop the resin crack is at the end of the first terminated flange ply from the last continuous skin ply. However, a matrix crack could develop inside the resin pocket due to defects in the resin pocket as seen in Figure 4 for the actual specimens. The location of the matrix crack in the resin pocket relative to the ply termination was anticipated to have an significant influence on the pull-off load. Therefore, in order to investigate the resin crack location effect, a crack in the resin pocket at a distance, $\delta$, from the end of the first terminated flange ply was introduced, and a delamination running from this crack was assumed. This idealized model also yielded increasing $G$ values with increasing delamination length.

\section{Results and Comparisons}

The calculated mixed mode ratio, $G_{\Pi} / G_{T}$, for all nine specimens are shown in Figure 15. The analytically predicted maximum pull-off loads are compared with the experimental ones in Figure 16. By modeling the as-manufactured microstructural details, the fracture mechanics analysis accurately predicts the experimental results for each specimen. The only exception is in specimen $3 \mathrm{~A} 3-3$ (15\%). For this specimen, the edge of the flange was rounded off during polishing, making it difficult to get an accurate mesh generation from the micrograph of the specimen edge. Forthermore the as-manufactured models of each individual specimen replicate the variablity observed in the test results indicating that it is the quality of the local details near the flange that control the strength and variablity in the pull-off load. 
The pull-off load predicted from the idealized analysis is plotted in Figure 17 as a function of the distance ( $\delta$ ) of the resin crack to the terminated ply, normalized by the ply thickness (h). Also appearing in the figure are test results for all but specimen $3 \mathrm{Al}-3$ because specimen $3 \mathrm{~A} 1-3$ has a unique two-ply termination. Figure 17 shows that the predicted pull-off load from the idealized model increases as $\delta$ increases, which indicates the resin crack is most likely to occur at $\delta=0$ for a perfect resin pocket. If there are defects in the resin pocket which results in a resin crack at $\delta>0$, the pull-off load predicted by $\delta=0$ gives a lower bound. On the other hand, there is no similar trend among the experimental results because each specimen has a unique resin pocket and ply waviness. Hence, to obtain an accurate prediction the as-manufactured details at the critical location need to be modeled. Therefore, the use of the MEGS software to model the as-manufactured microstructure may be very useful in general to assess the effects of defects on delamination onset and growth in composite structures.

\section{Concluding Remarks}

Hat stringer pull-off tests were performed on nine rod-reinforced hat stringer specimens. The failed specimens were examined by microscope, revealing that the delamination initiated and grew from a resin crack at the end of a terminated flange ply from the continuous skin plies. Test results indicated that the as-manufactured microstructure in the flange region has a strong influence on the delamination initiation and the associated pull-off loads. The as-manufactured specimens had smaller resin pockets than the as-designed specimen. In most cases, delamination initiated at the first ply termination from the continuous skin plies and the terminated flange plies seperated from the continuous skin plies. Two of the three specimens with a resin pocket that cracked away from the terminated ply had the lowest pull-off loads. Specimens with the most waviness (most compaction under the flange) had the lowest pull-off loads. 
Finite element models were created for each specimen with a detailed mesh based on micrographs of the critical location. A fracture mechanics approach and a mixed mode delamination criterion were used to predict the onset of delamination and the pull-off load. An idealized model was developed based on the as-designed microstructure of the skin-flange region. This idealized model applied to the as-designed microstructure was not adequate for these hat stringer pull-off geometries because the as-manufactured microstructure had anomalies such as resin pockets, ply termination and ply waviness. However, a fracture mechanics approach based on finite element models of the as-manufactured microstructure was able to accurately predict the hat stringer pull-off loads and replicate the variabilty in the test results.

As a result of this study, two recommendations concerning the manufacture of these specimens are offered to ensure the highest possible pull-off strength. Steps must be taken to first, achieve uniform compaction (ie, no waviness under the flange tip), and second, to ensure good quality (ie, no flaws or voids) in the resin pocket at the terminated flange ply closest to the skin.

\section{Acknowledgment}

This work was performed while the first author was a National Research Council Research Associate with the Army Research Laboratory Vehicle Structures Directorate at NASA Langley Research Center. This work was performed under a Cooperative Research and Development Agreement between Bell Helicopter Textron and the U.S. Army Research Laboratory Vehicle Structures Directorate at NASA Langley.

\section{References}

[1] Baker, D. J., Nunn, K. E., Rogers, C. W., Dompka, R. V., and Holzwarth, R. C., "Design, Development and Test of a Low-Cost, Pultruded-Rod-Stiffened Wing Concept and Its Application to a Civil Tilt Rotor Transport," 10th DOD/NASA/FAA 
Conference on Fibrous Composites In Structural Design, Hilton Head, SC, November, 1993.

[2] Rousseau, C. Q., Baker, D. J., and Chan, W. S., "Analysis and Testing of a Graphite Rod-Reinforced Hat-Section Stringer," 36th Structures, Structural Dynamics and Materials Conference (SDM), New Orleans, April, 1995.

[3] Anderson, T. L., Fracture Mechanics: Fundamentals and Applications, Second Edition, CRC Press, Boca Raton, 1995, pp. 41-43.

[4] D 5528-94a, Standard Test Method for Mode I Interlaminar Fracture Toughness of Unidirectional Fiber-Reinforced Polymer Matrix Composites, 1995 Annual Book of ASTM Standards, Vol. 15.03, pp. 280-289.

[5] Russell, A. J., "On the Measurement of Mode II Interlaminar Energies," DREP Materials Report 82-0, Defense Research Establishment Pacific, Victoria, BC, 1982.

[6] O'Brien, T. K., Murri, G. B. and Salpekar, S. A., "Interlaminar Shear Fracture Toughness and Fatigue Thresholds for Composite Materials," Composite Materials: Fatigue and Fracture, Second Volume, ASTM STP 1012, April, 1989, pp. 222-250.

[7] Reeder, J. R. and Crews, J. H., "Mixed-Mode Bending Method for Delamination Testing," AIAA Joumal, Vol. 28, No. 7, pp. 1270-1276, 1990.

[8] Rybicki, E. F. and Kanninan, M. F., "A Finite Element Calculation of Stress Intensity Factors by a Modified Crack-Closure Integral," Engineering Fracture Mechanics, Vol. 9, pp. 931-938, 1977.

[9] Raju, I. S., Crews, Jr, J. H., Aminpour, M. A, "Convergence of Strain Energy Release Rate Components for Edge-Delaminated Composite Laminates," Engineering Fracture Mechanics, Vol. 30, No. 3. pp. 383-396, 1988. 
Table 1 Maximum Pull-off Loads Normalized by Specimen Width.

\begin{tabular}{ll}
\hline Specimen & Pull-off Load $(\mathrm{kN} / \mathrm{m})$ \\
\hline $3 \mathrm{~A} 1-3$ & 15.15 \\
$3 \mathrm{~A} 3-2$ & 20.72 \\
$3 \mathrm{~A} 1-2$ & 21.01 \\
$3 \mathrm{~A} 2-6$ & 22.76 \\
$3 \mathrm{~A} 2-3$ & 23.77 \\
$3 \mathrm{~A} 2-2$ & 23.82 \\
$3 \mathrm{~A} 1-1$ & 25.21 \\
$3 \mathrm{~A} 3-1$ & 27.03 \\
3A3-3 & 28.46 \\
\hline Mean & 23.10 \\
\hline Standard Deviation & 3.92 \\
\hline Coefficient of Variation & $17 \%$ \\
\hline
\end{tabular}

Table 2. Material properties.

\begin{tabular}{ll}
\hline Materials & Properties \\
\hline IM7/E7T1-2 & $\mathrm{E}_{11}=163 \mathrm{GPa}$ \\
& $\mathrm{E}_{22}=9.65 \mathrm{GPa}$ \\
& $\mathrm{G}_{12}=5.52 \mathrm{GPa}$ \\
& $\mathrm{v}_{12}=0.33$ \\
\hline Neat Resin & $\mathrm{E}=3.45 \mathrm{GPa}$ \\
& $\mathrm{v}=0.41$ \\
\hline
\end{tabular}


Rubber Pad

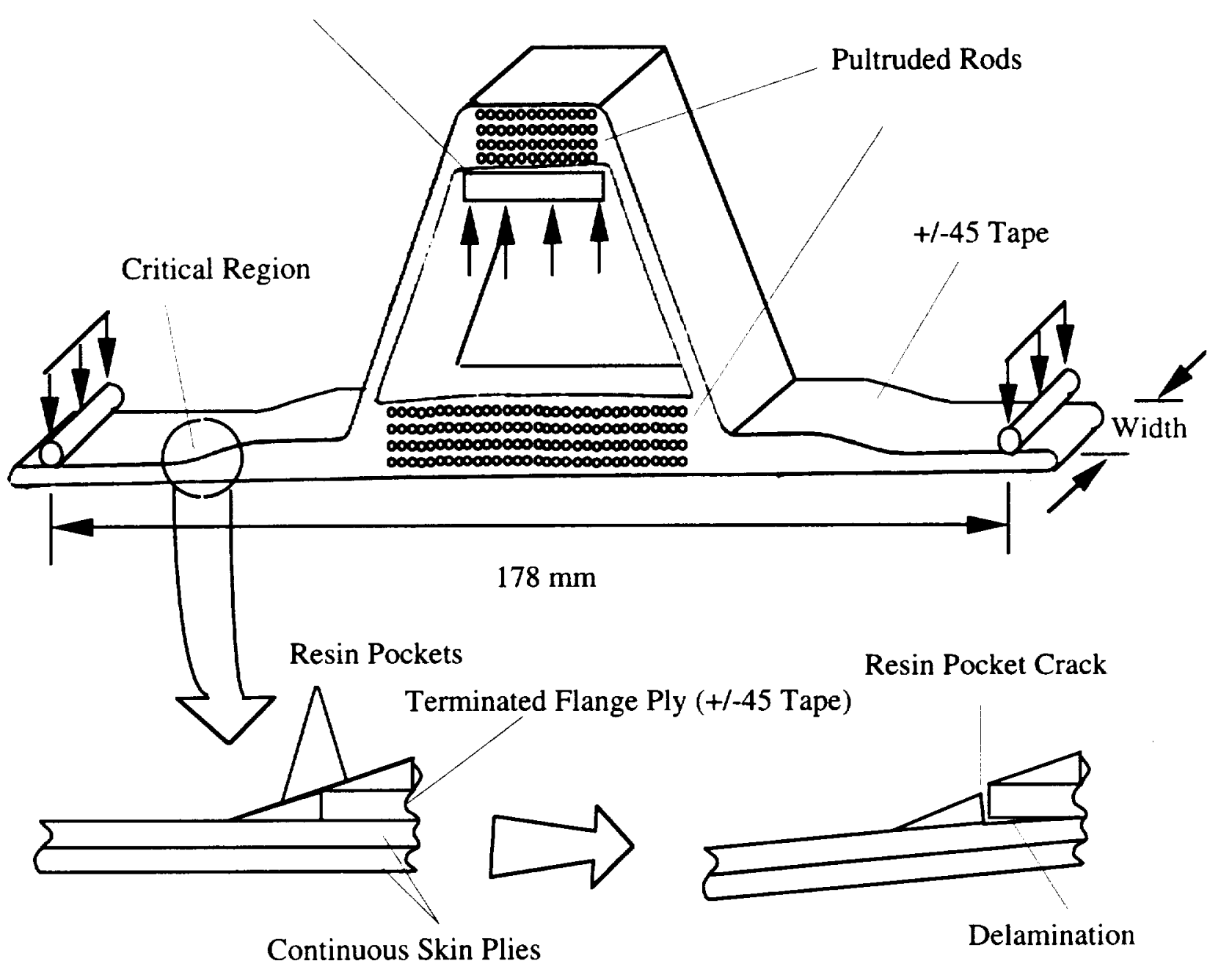

Figure 1. Hat Stringer Pull-off Test Configuration and Initial Delamination Location. 


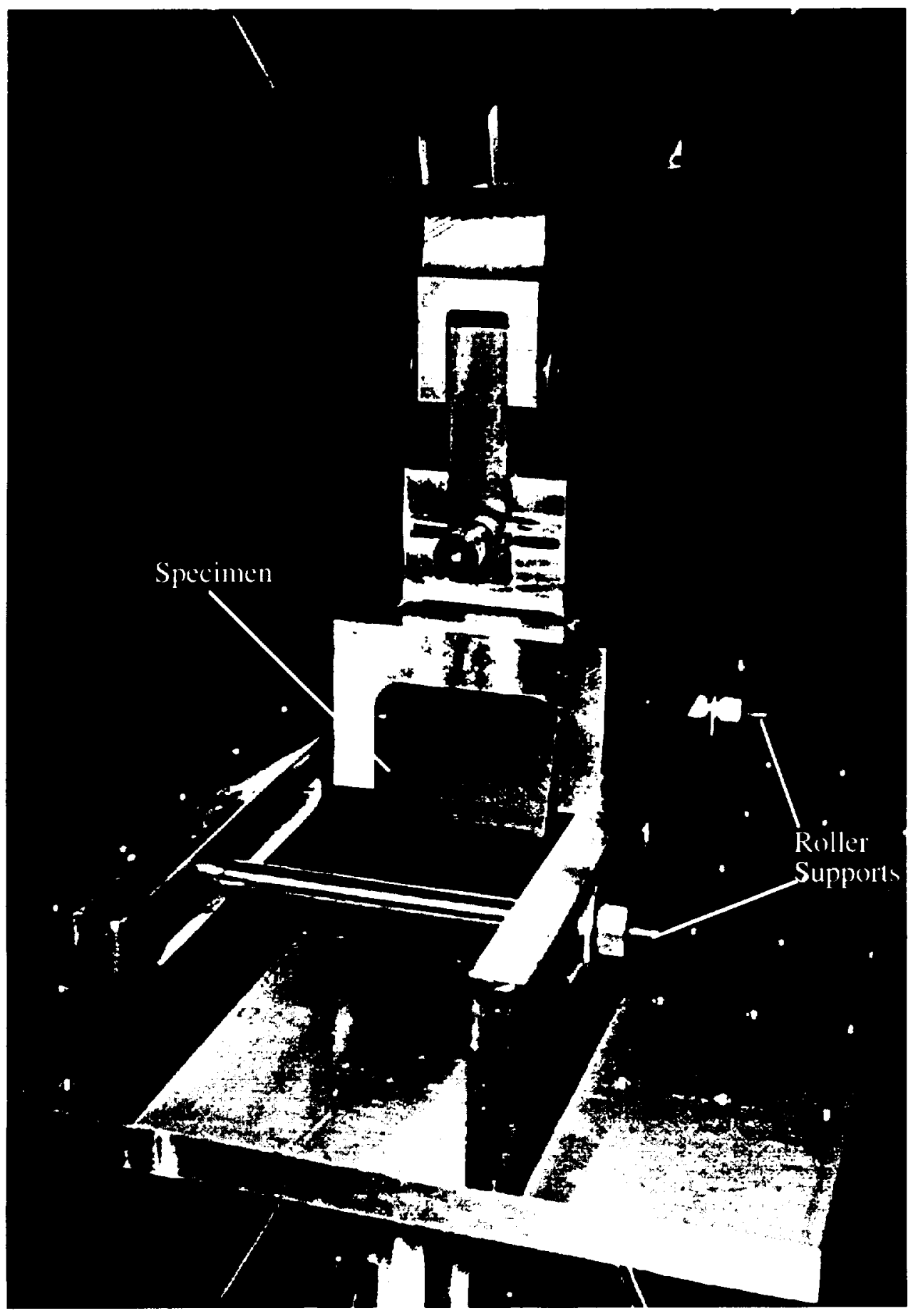

Figure 2. Hat Stringer Pull-off Test Fixture with a Specimen in Place 


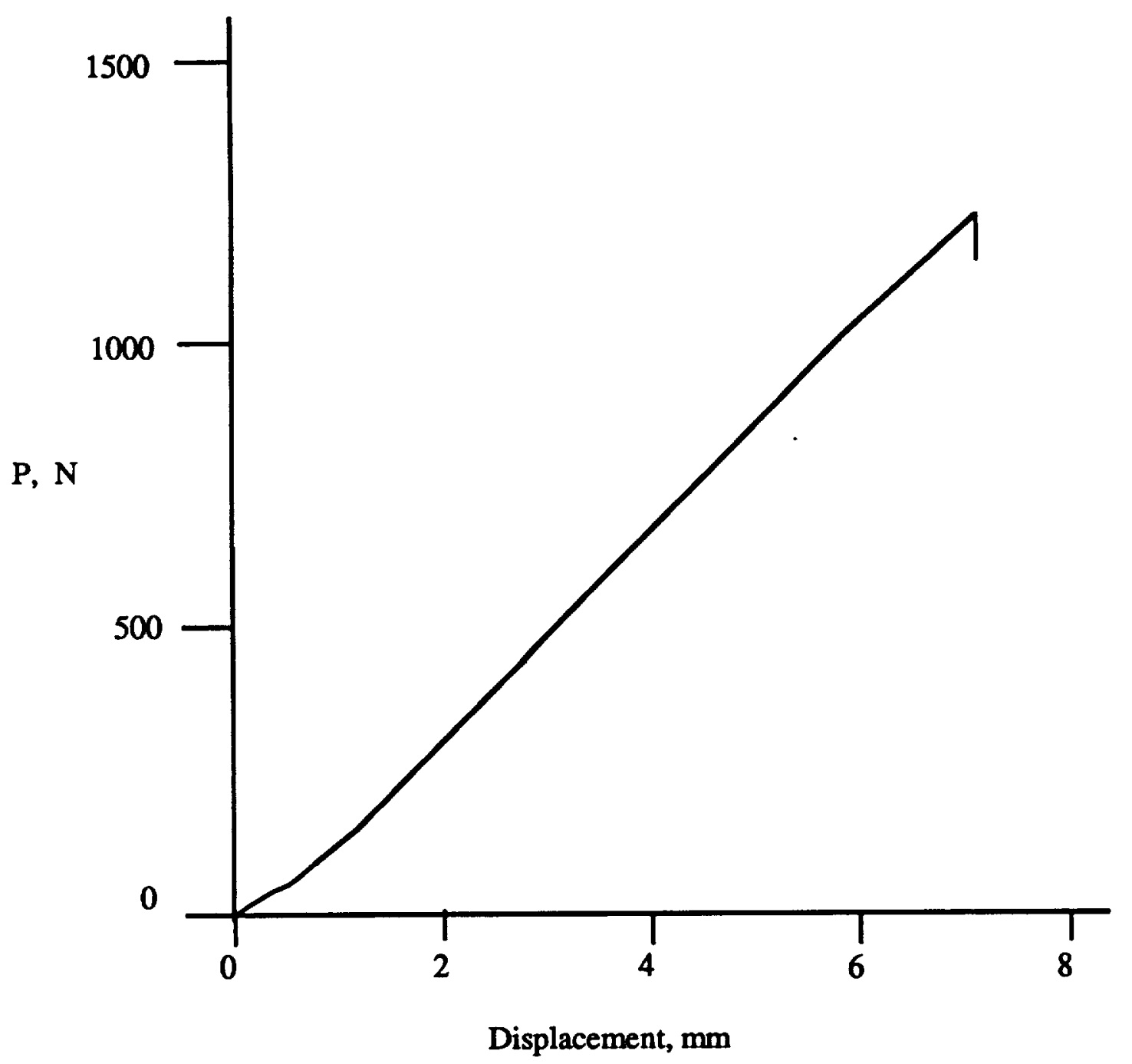

Figure 3. Typical Load-Displacement Curve 

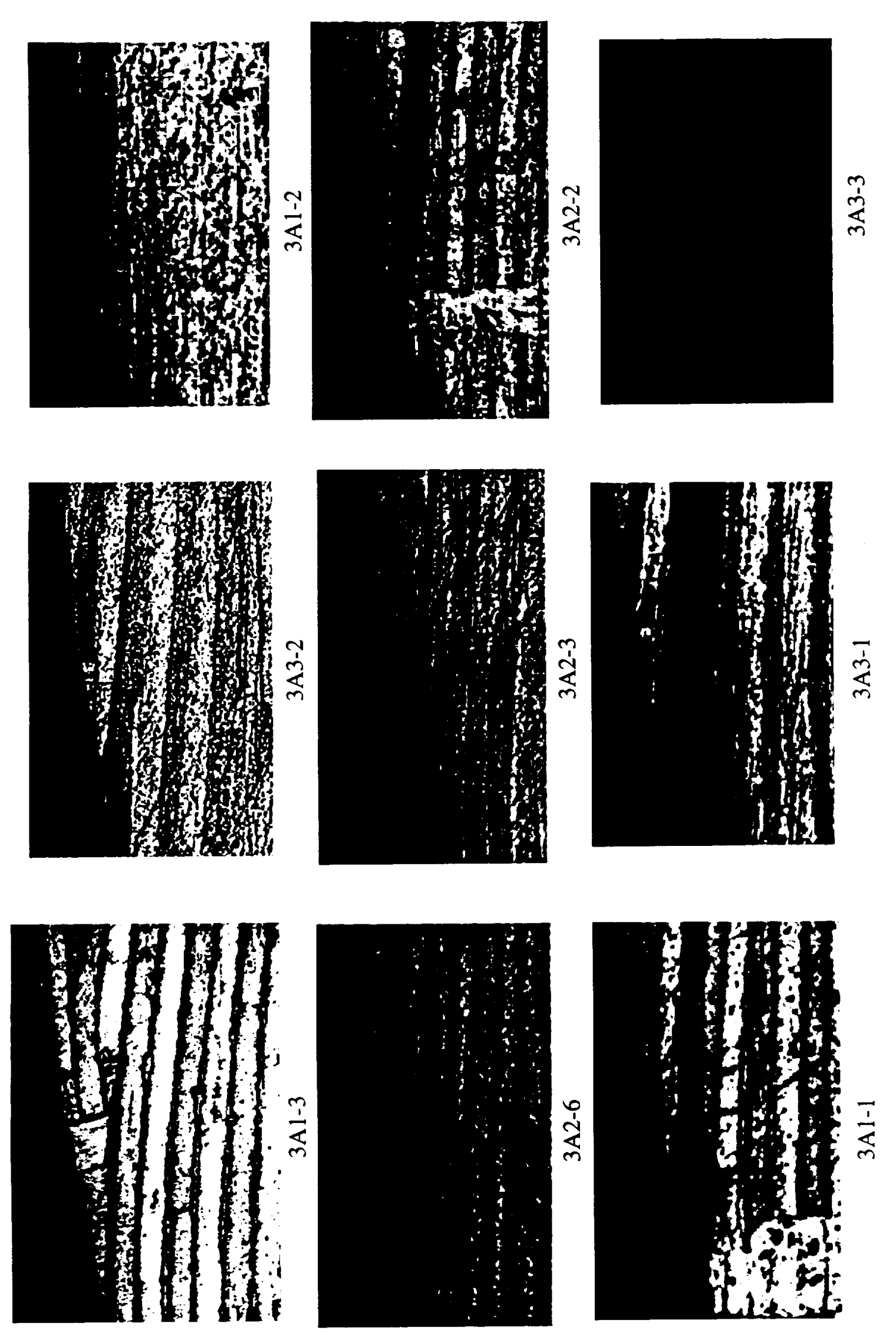

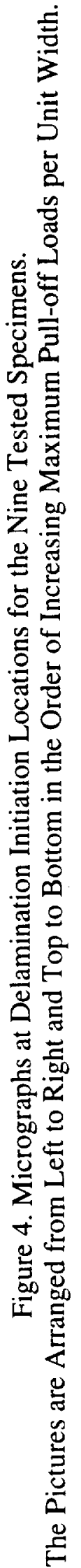




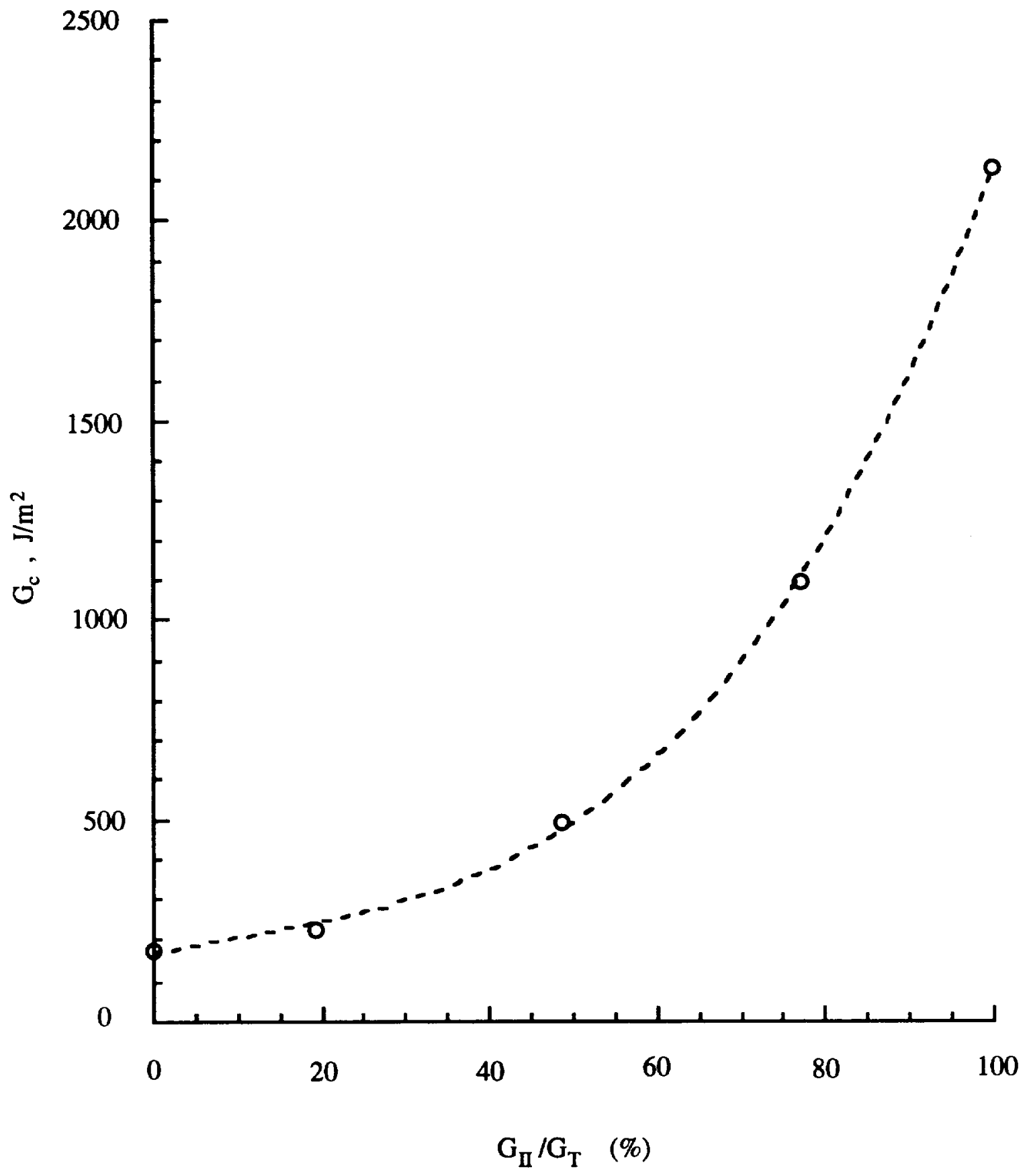

Figure 5. Mixed Mode Delamination Criterion for IM7/E7T1-2 Graphite/Epoxy Composites. 

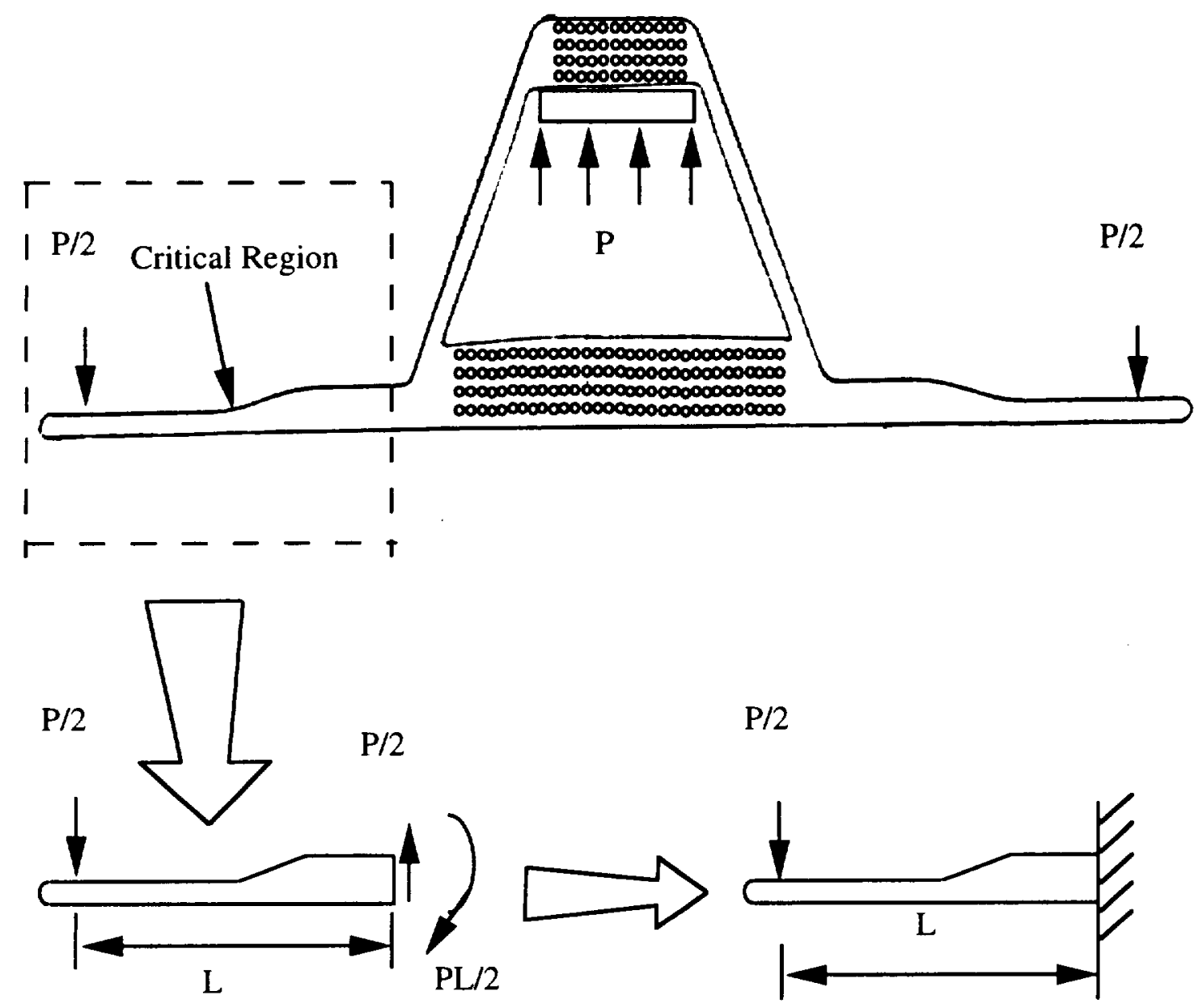

Figure 6. Model of the Skin-Flange Region 


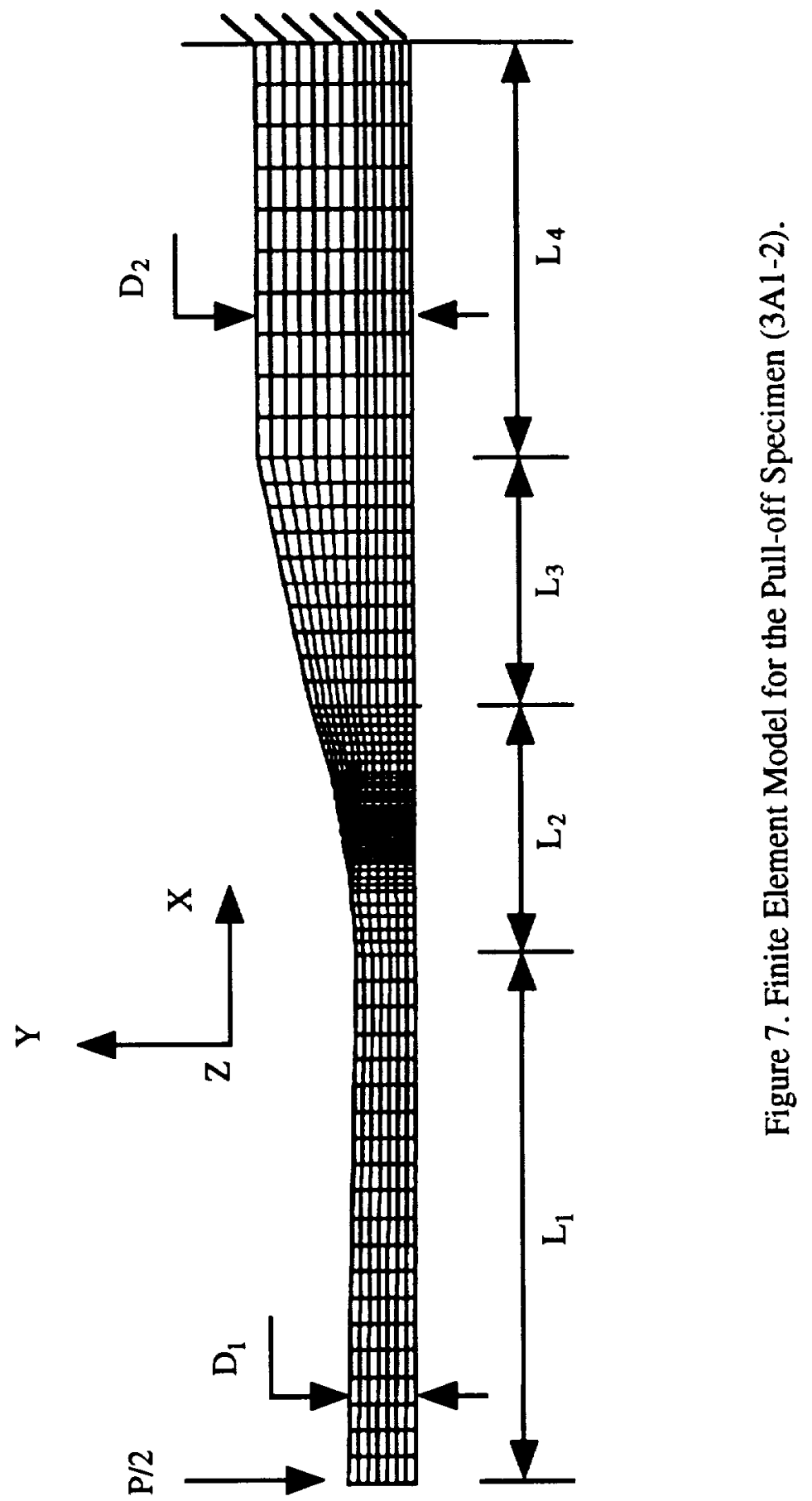




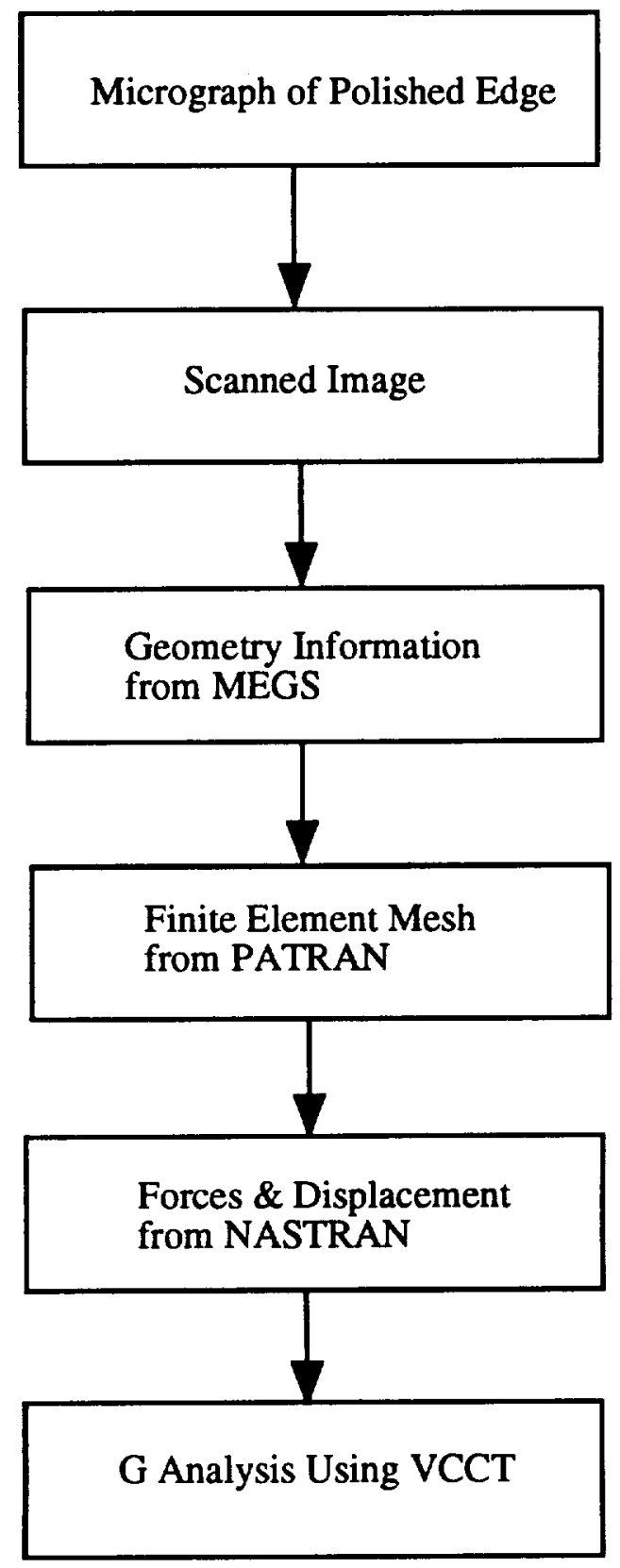

Figure 8. Process for Analysis of As-manufactured Microstructure in Hat Stringer Pull off Specimens 


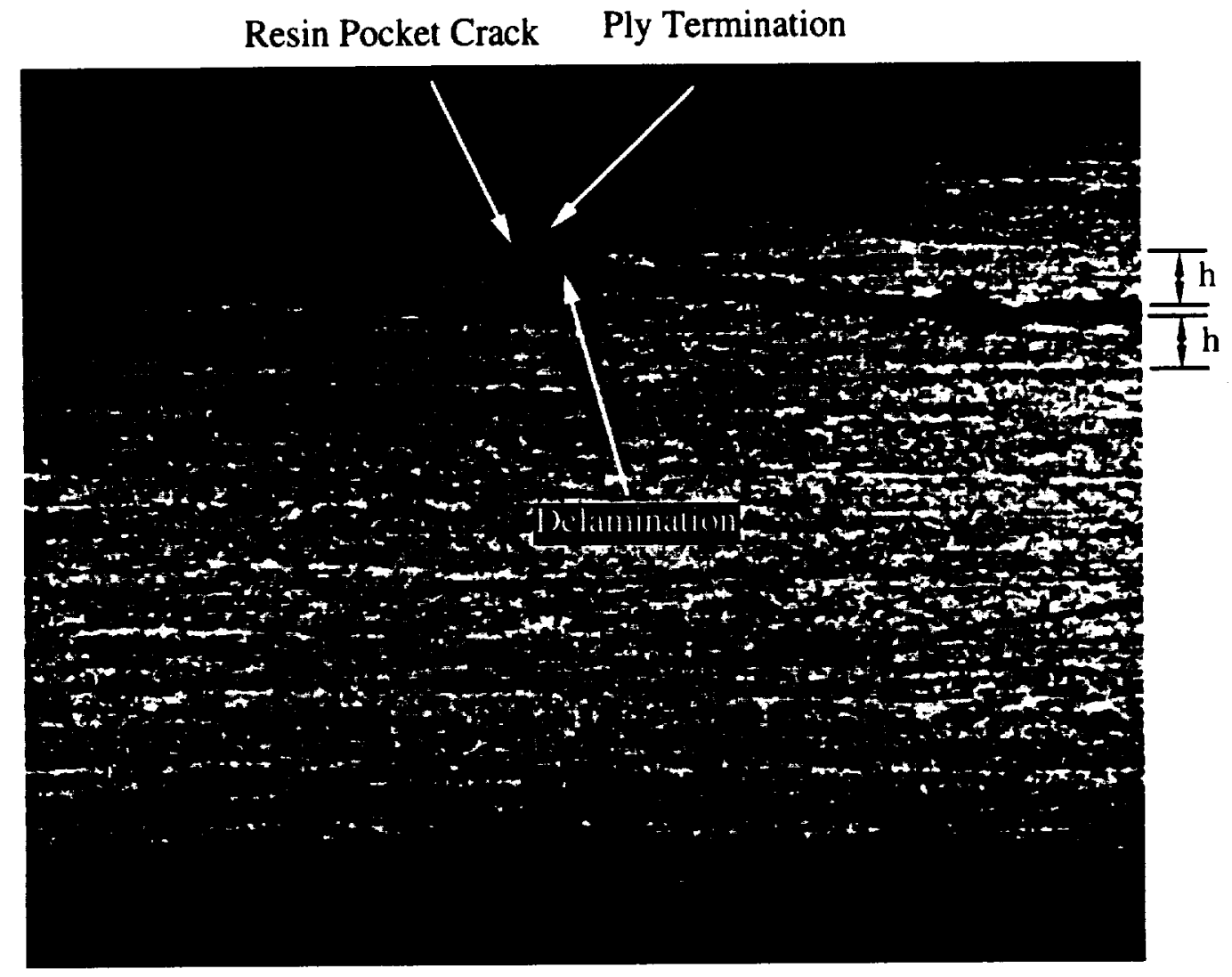

Figure 9. Photomicrograph of the Flange Tip Region for Specimen 3A1-2. 
- Multipoint Constraint (MPC)

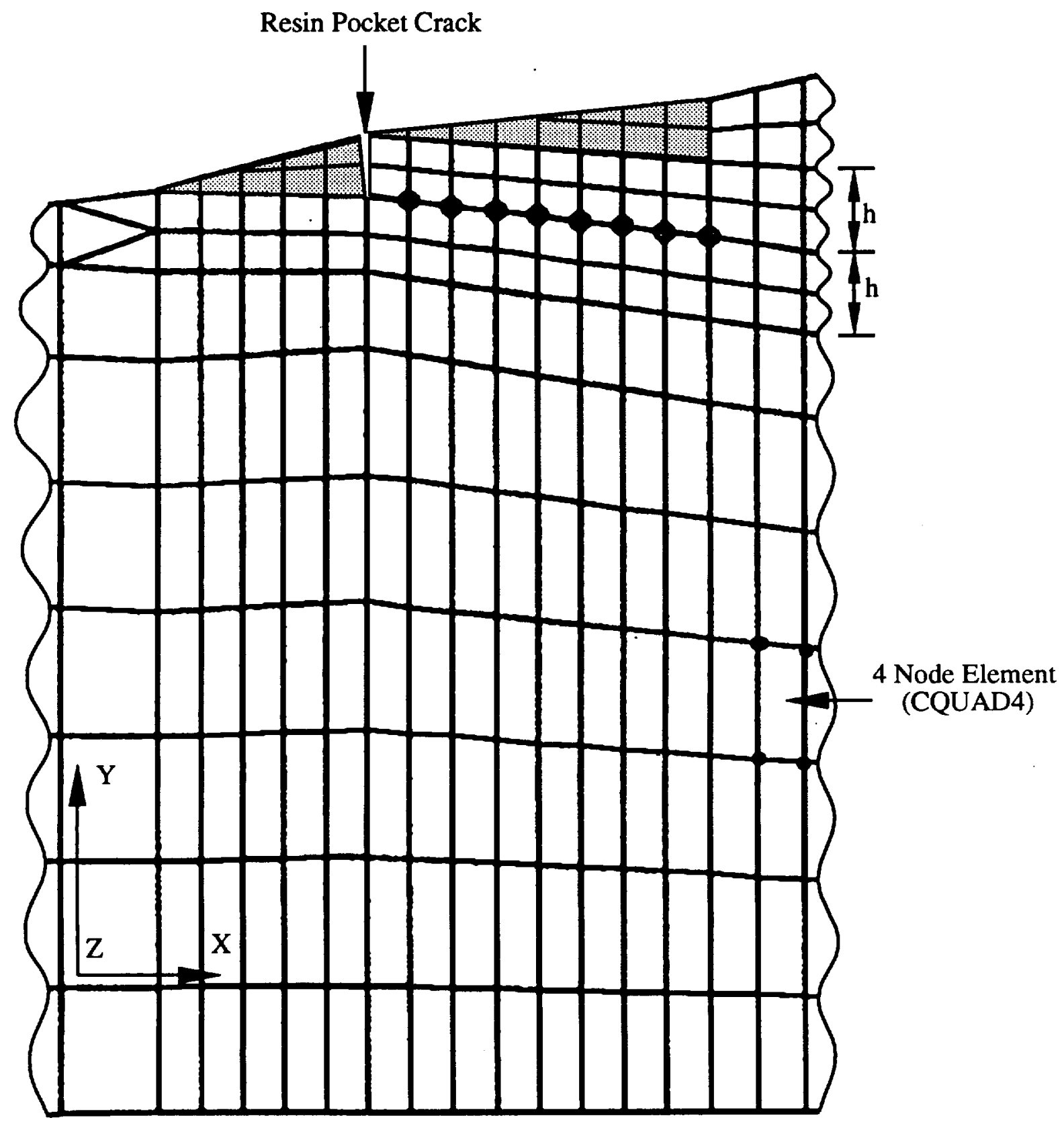

Figure 10. Detailed Finite Element Mesh of As-manufactured Microstructure at the Flange Tip Region for Specimen 3A1-2. 


\section{Resin Pocket Crack Terminated Plies}

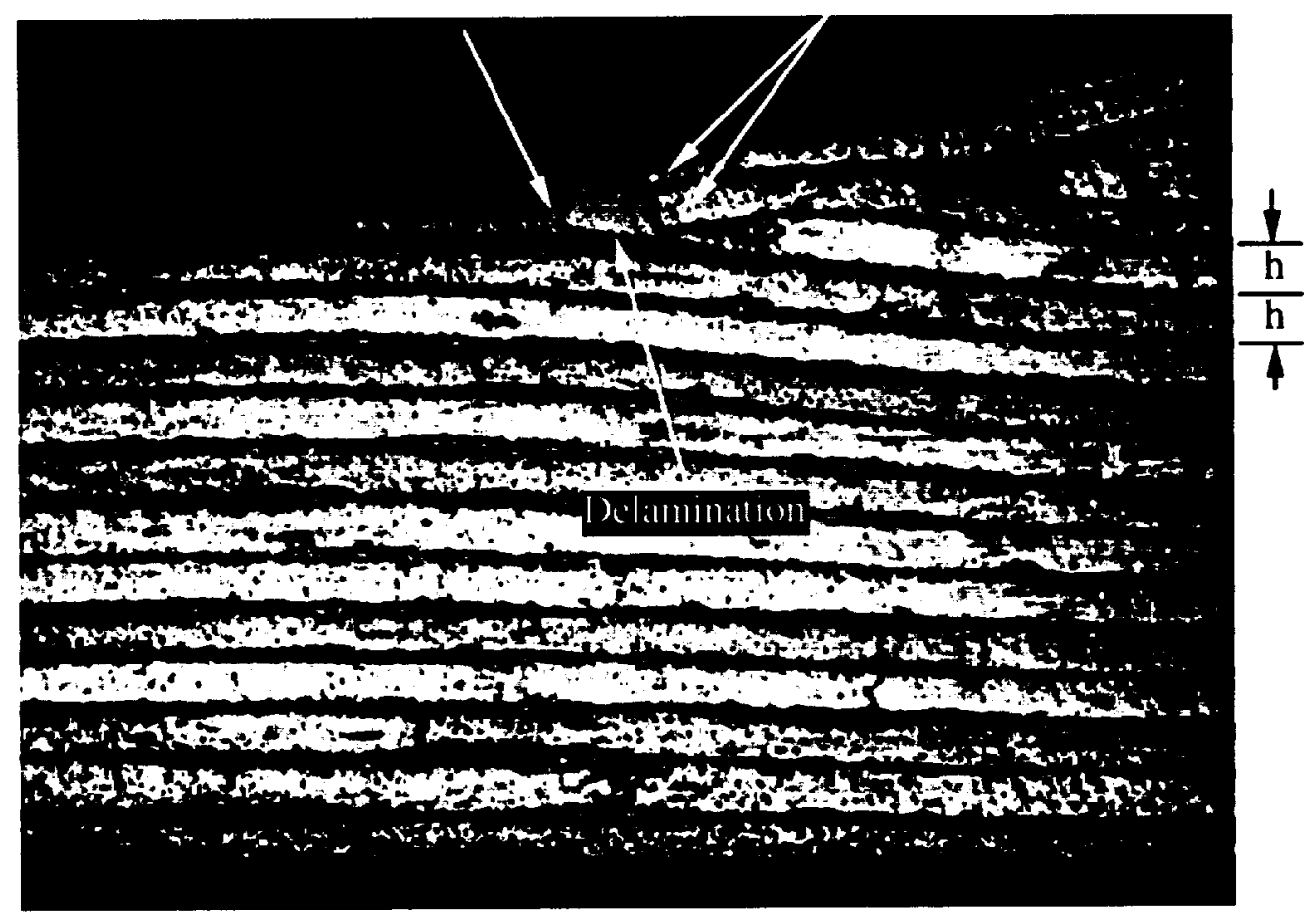

Figure 11. Photomicrograph of the Flange Tip Region for Specimen 3A1-3. 


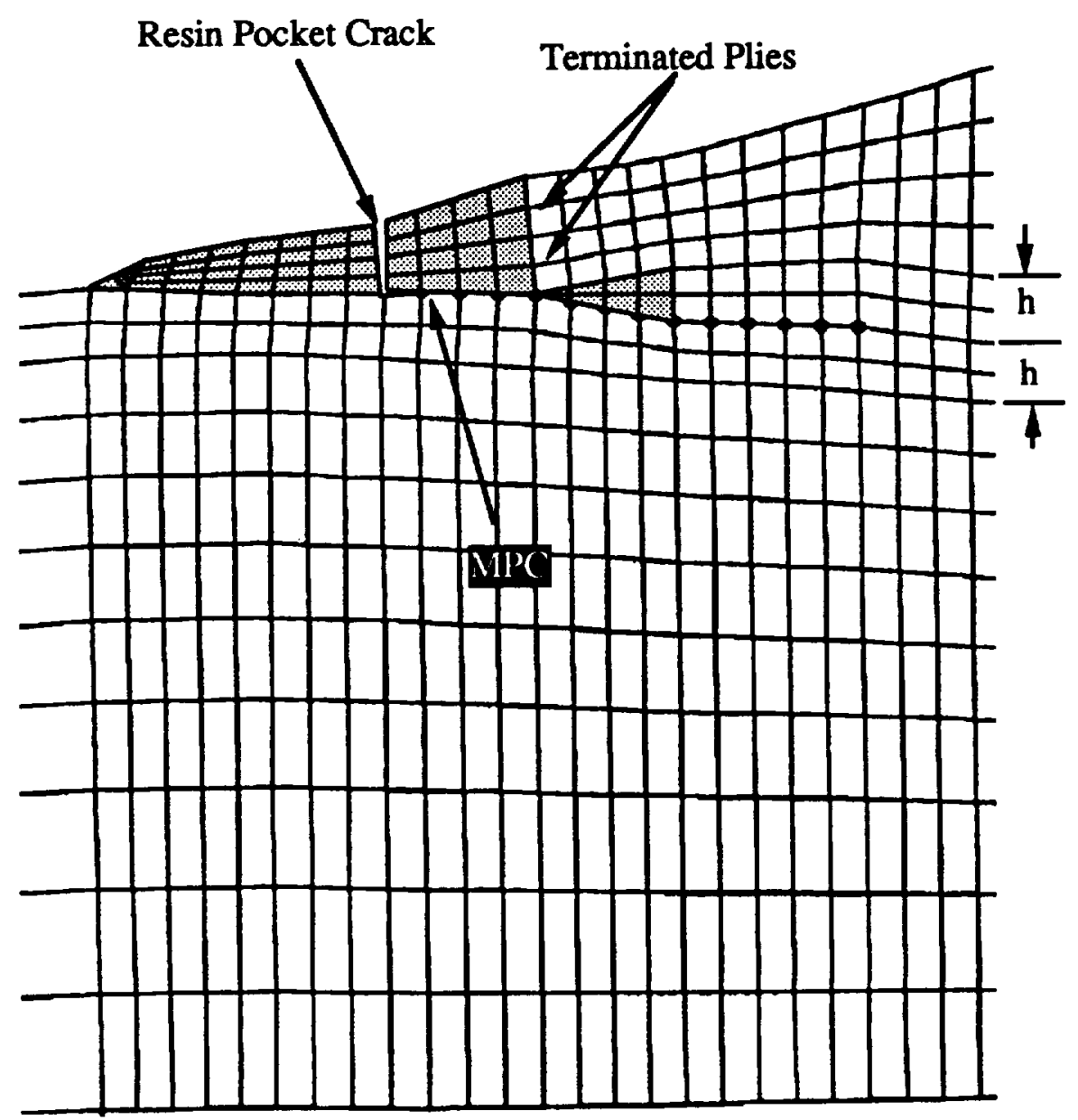

Figure 12. Detailed Finite Element Mesh of As-manufactured Microstructure at the Flange Tip Region for Specimen 3A1-3. 


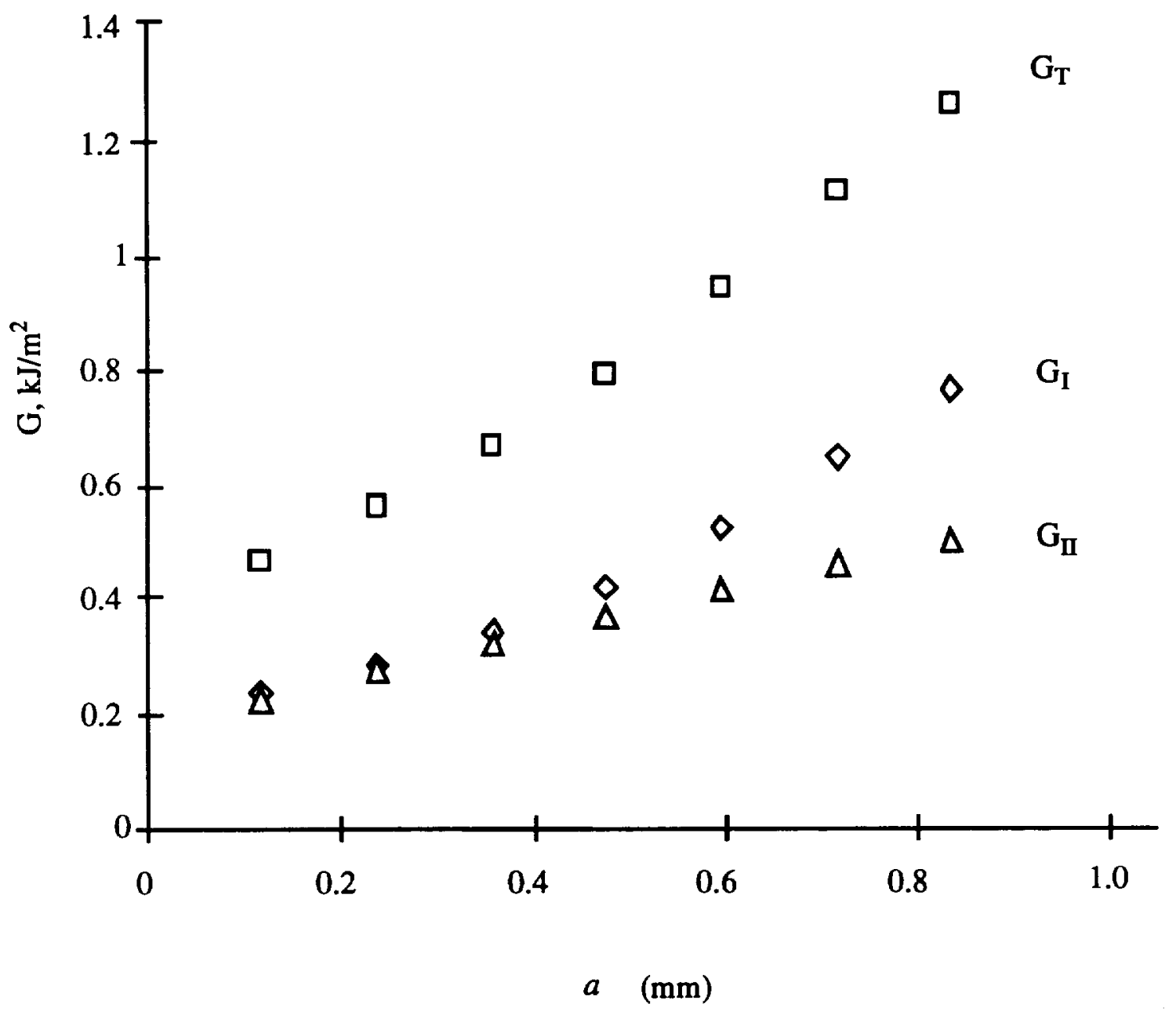

Figure 13. Total Strain Energy Release Rate and its Components for a Specimen 3A1-2. 
- Multipoint Constraint (MPC)

Crack in First Resin Pocket

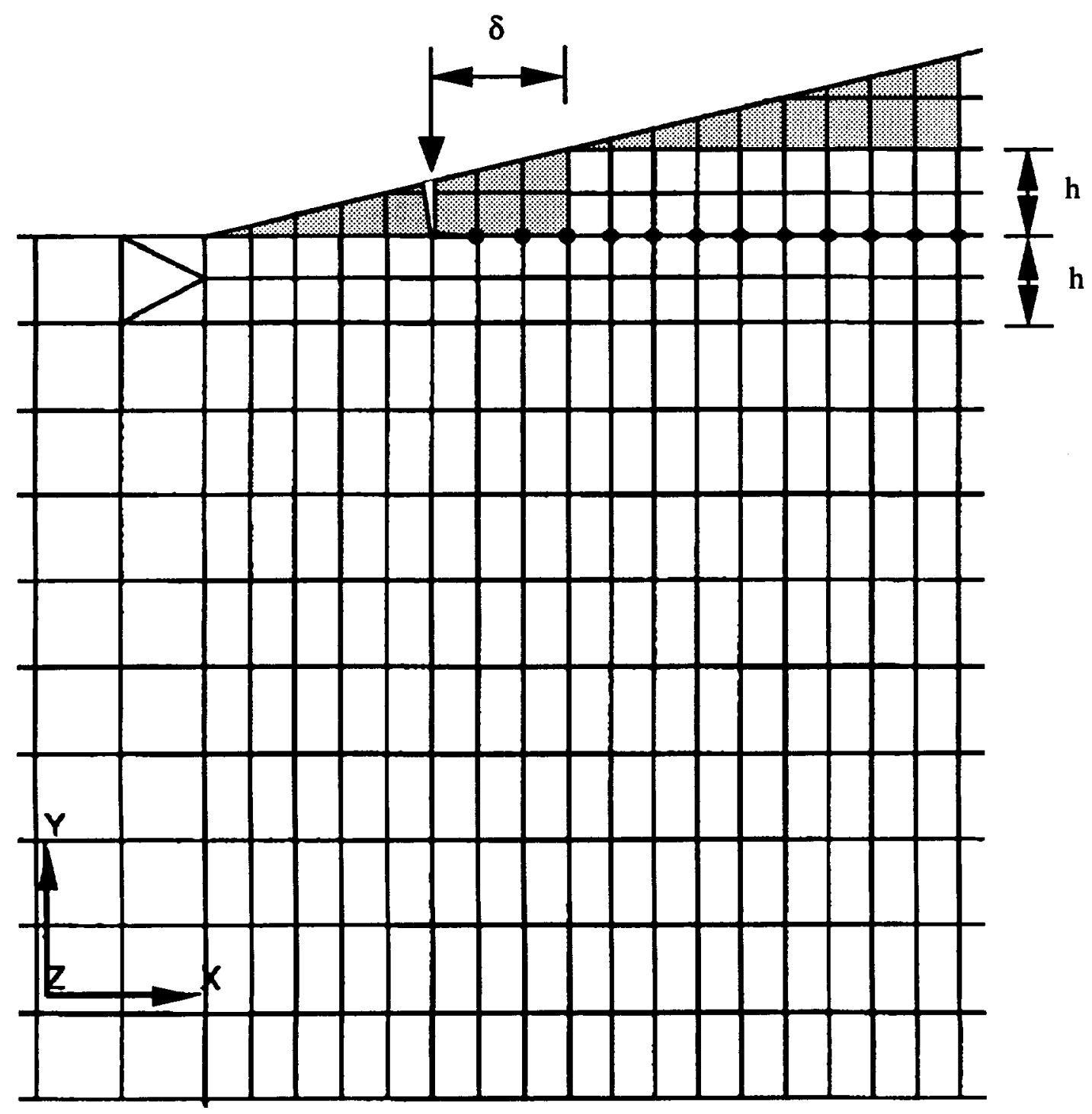

Figure 14. Detailed Finite Element Mesh for the Idealized Specimen. 


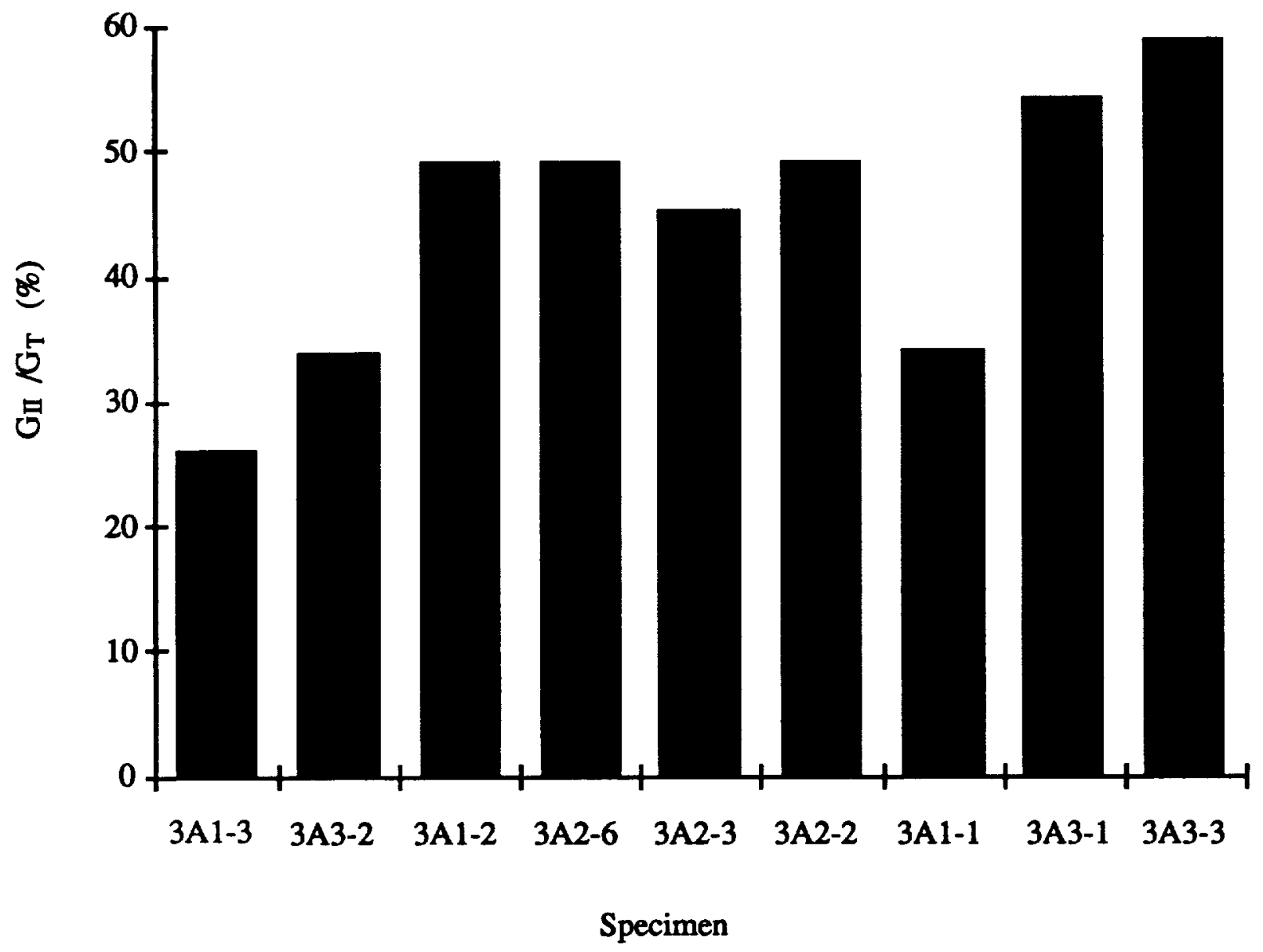

Figure 15. Predicted Mode II to Total Strain Energy Release Rate Ratios. 


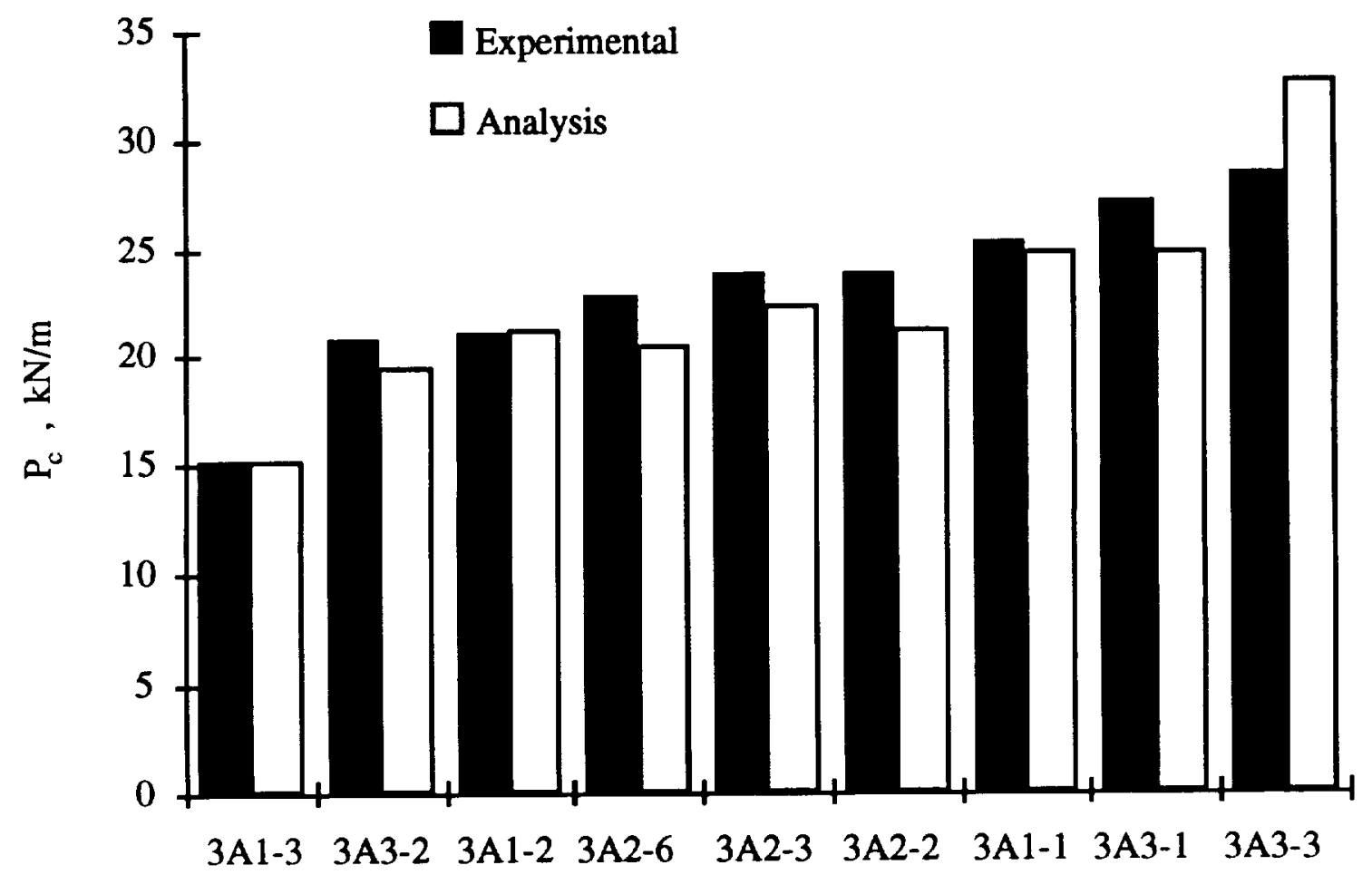

Figure 16. Comparisons of Analysis to Experimental Results of Maximum Pull off Loads. 


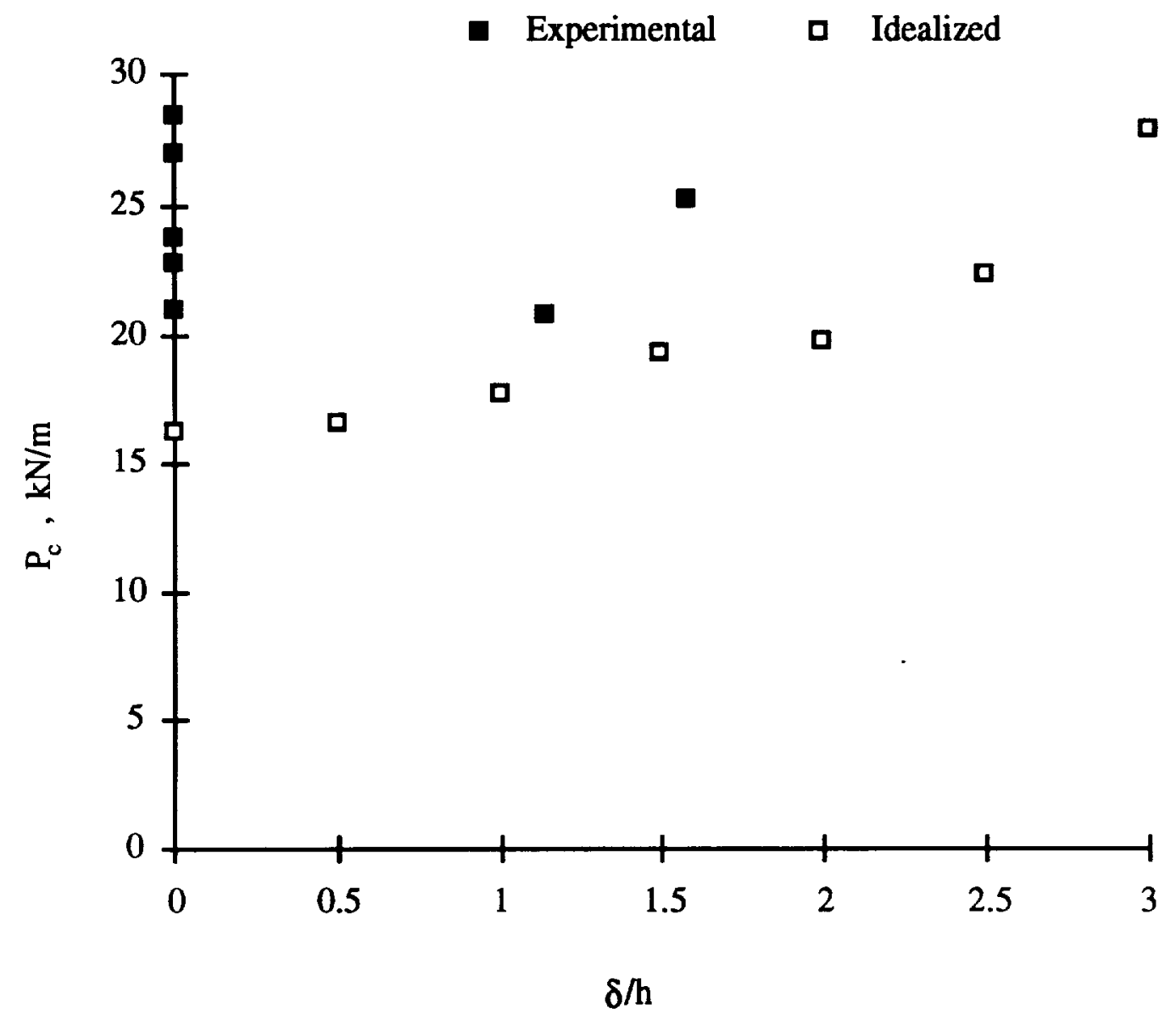

Figure 17. Comparison of the Idealized Analysis and Experimental Results. 


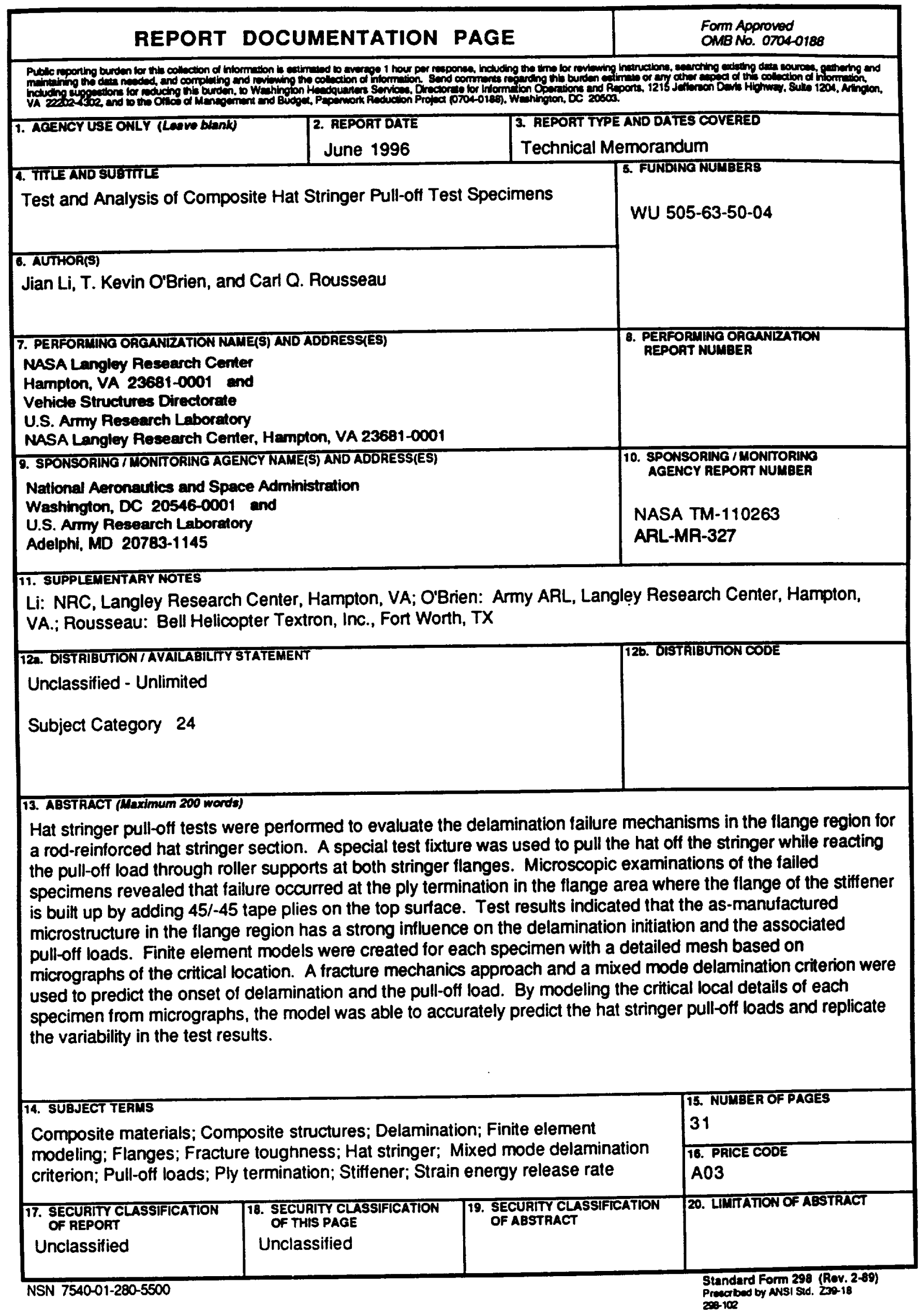

